\title{
Use of materials in nest construction by Pied Flycatchers Ficedula hypoleuca reflects localized habitat and geographical location
}

\section{Kevin B. Briggs \& D. Charles Deeming}

To cite this article: Kevin B. Briggs \& D. Charles Deeming (2016): Use of materials in nest construction by Pied Flycatchers Ficedula hypoleuca reflects localized habitat and geographical location, Bird Study

To link to this article: http://dx.doi.org/10.1080/00063657.2016.1238867

曲 Published online: 30 Sep 2016.

Submit your article to this journal

Q View related articles $\longleftarrow$

View Crossmark data $־$ 


\title{
Use of materials in nest construction by Pied Flycatchers Ficedula hypoleuca reflects localized habitat and geographical location
}

\author{
Kevin B. Briggs ${ }^{a}$ and D. Charles Deeming ${ }^{b}$ (D) \\ ${ }^{a}$ Independent Researcher, Carnforth, Lancashire, UK; ${ }^{b}$ Joseph Banks Laboratories, School of Life Sciences, University of Lincoln, Lincoln, UK
}

\begin{abstract}
Capsule: Pied Flycatchers Ficedula hypoleuca use different materials to construct their nests according to local availability and geographical location.

Aims: This study tested the hypotheses that Pied Flycatcher nests were constructed from the leaves of different tree species in proportion to their occurrence within the breeding territories and that nest composition varied between geographical locations.

Methods: In Lancashire, Pied Flycatcher nests were collected from nestboxes built in locations dominated by different tree species and were deconstructed to determine which materials were used.

Results: The leaves found in nests generally reflected their availability within the locality of the territories rather than showing evidence of selective use of some leaf species. However, the use of moss was dominated by the use of one species in all but two nests. Nests from Lancashire were significantly different in composition when compared with published data for nests from north Wales and central Spain.

Conclusion: Pied Flycatchers exhibit plasticity in nest construction behaviour because they were opportunistic in their choice of most leaves as nesting materials, although they may be selective in their choice of moss.
\end{abstract}

ARTICLE HISTORY

Received 19 April 2016

Accepted 16 September 2016
Construction of nests is a plastic behaviour in birds (Deeming \& Mainwaring 2015). Individual birds do not construct nests in the same way (Walsh et al. 2011) and nests constructed in one location can vary according to time of building or temperature (Britt \& Deeming 2011, Deeming \& Mainwaring 2015). Nest materials used during construction can also vary between geographical locations, for example, in Great Tits Parus major (Álvarez et al. 2012). The materials used in a nest can correlate with the functional properties of a nest, for example, Common Blackbirds Turdus merula use more dry grass in better insulated nests (Mainwaring et al. 2014). The choice of materials used in different parts of the nest is also different with materials used in cups varying from those of the nest base, as seen in the European Robin Erithacus rubecula (Taberner Cerezo \& Deeming 2016), and the size, strength and rigidity of the materials can also vary in different parts of the nest (Biddle et al. 2015, forthcoming). In some instances, birds include fresh leaves from specific plants that have anti-microbial properties or which discourage ectoparasites in their nests (Dubiec et al. 2013).
There is evidence that selection of materials is opportunistic. For instance, use of wool in Great Tit nests varied between years and seemed to reflect the proximity of sheep to the nesting woodlands (Britt \& Deeming 2011). In an experiment, Surgey et al. (2012) provided tit species (Paridae) with differently coloured, artificial materials that they used in their nests. The extent to which the various colours were used depended on the distance between the location of the materials dispenser and the nestbox. The closer the distance, the more materials were used. Use of anthropogenic materials in nests also seems to be deliberate but opportunistic. Cigarette butts were used in nests by House Sparrows Passer domesticus and House Finches Carpodacus mexicanus nesting in urban environments (Suárez-Rodríguez et al. 2013). Other instances do seem to suggest that selection of material is more deliberate. For example, use of pieces of white plastic by Black Kites Milvus milvus was seen as being a sexual signal and is age-dependent (Sergio et al. 2011). In addition, Rock Sparrows Petronia petronia actively carried feathers to their nests seemingly to act as a signal between conspecifics (García-Navas et al. 2015). 
Despite these reports we have little understanding of whether birds have preferences for particular nest materials. Compared to Great Tits, Blue Tits Cyanistes caeruleus seem to prefer feathers over hair to line their nests (Perrins 1979, Britt \& Deeming 2011) but we have no idea of the efforts that individuals will use to find particular materials. Surgey et al. (2012) found no evidence that tits were travelling further to select materials of a particular colour of material. However, if birds were seeking out particular nesting materials, for example leaves of a particular species, they would presumably pay a cost of exploring for such materials over a wider area rather than using what could be seen as a comparable material closer to the nest site, such as leaves of a second species within the birds' territories. Hence, the feathers collected by Rock Sparrows did not appear to serve any thermoregulatory role yet they were associated with the extra energetic effort of collection and there could an increased risk of predation (García-Navas et al. 2015).

Pied Flycatcher Ficedula hypoleuca nests are regularly built within nestboxes in upland woods making them a good subject to study. A variety of plant materials are found in Pied Flycatcher nests (Stjernberg 1974, Lundberg \& Alatalo 1992) but data collected for nests in Wales show that there is a high proportion of tree leaves used (Deacon et al. cited by Deeming \& Mainwaring 2015). By contrast, Pied Flycatchers in central Spain seem to prefer grass over tree leaves in their nests (Moreno et al. 2009, Cantarero et al. 2013). It is unclear whether this difference in the use of materials reflects either: general plasticity in choice of materials used in nest construction, variability in the availability of materials, differences in the properties of the materials used, or a difference in preference for materials in these geographically separated populations. This study sought to tease apart these possibilities by exploring the role of material choice in nest construction behaviour of Pied Flycatchers nesting in mixed woodland in Lancashire, England. In our study the nature of the woodland meant that birds were occupying nestboxes in areas dominated by one or two species of tree. This provided an opportunity to investigate whether the birds had a preference for leaves from a particular tree species, which they would have to travel greater distances to collect, or if the birds simply used the leaves nearest to the nestbox. We predicted that the birds would use leaves in proportion to their encounter rate within their breeding territories and tested this by comparing the proportions of leaves available, based on tree numbers, against the proportion of leaves used in nests. We also used these data to explore geographical variation in nest material use, by testing whether Pied Flycatchers in Lancashire were using different materials in their nests compared with those from Wales and Spain.

\section{Methods}

Twenty-five Pied Flycatcher F. hypoleuca nests were collected from five woodland sites in northwest Lancashire, England $\left(54^{\circ} 05^{\prime} \mathrm{N}, 2^{\circ} 36^{\prime} \mathrm{W}\right.$, altitude $=100$ $190 \mathrm{~m}$ above sea level) in late June and early July 2015 . The woods are deciduous, with some additional conifer plantations, but within them are areas (measuring at least $50 \times 100 \mathrm{~m}$ ) of four different types dominated mainly by one tree species, that is, birch Betula sp. $(n=2)$, alder Alnus glutinosa $(n=4)$, oak Quercus sp. $(n=10)$ and mixed oak and birch $(n=9)$, that give the birds a specific characteristic for the nesting territory habitat. The birds were supplied with wooden nestboxes of identical construction (internal floor dimensions of $140 \times 95 \mathrm{~mm}$; distance from nest floor to hole of $105 \mathrm{~mm}$ ) so that all birds had the same base area and box volume in which to build a nest. Boxes were placed approximately $50 \mathrm{~m}$ apart and at $1.5 \mathrm{~m}$ above the ground, attached to a tree trunk and facing in a southerly or easterly direction except when topographical characteristics did not allow this. The boxes had been cleaned out the previous autumn and at the start of the 2015 season the boxes were monitored every five days to ensure that other bird species had not started and abandoned a nest.

A quantitative assessment of the distribution of tree species in the woodland types was made by identifying and counting the number of trees within a $25 \mathrm{~m}$ radius of the tree to which the occupied nestbox was attached. The count included the tree holding the nestbox. This area corresponds to approximately $1960 \mathrm{~m}^{2}$, which is equivalent to the upper range of the territory size reported for Pied Flycatchers (Cramp \& Perrins 1993).

All the boxes were checked at least once a week from the beginning of April following a nest recording protocol (British Trust for Ornithology Nest Record Scheme; Cooper et al. 2015). After completion of the nesting attempt the nest was removed, sealed in a labelled plastic bag and then frozen for 4 days at $-20^{\circ} \mathrm{C}$ to kill any invertebrates (Britt \& Deeming 2011). The nests were then air-dried in separate plastic trays and stored in a cool, dry environment until processing.

The tightly woven inner nest cup is easily recognized from the looser outer nest and was then carefully removed from the outer nest and treated separately thereafter. The nests were deconstructed further to quantify the various types of materials used during construction. After completion of deconstruction the 
separated components were weighed on an electronic balance (Pesola PPS200) to the nearest $0.01 \mathrm{~g}$. Any debris left, which was difficult to classify into a particular material, was sieved $(0.1 \mathrm{~mm}$ mesh $)$ to separate recognizable fragments from the accumulated nest and nestling debris, which was classified as 'dust' (Britt \& Deeming, 2011) and weighed. To counter the effect of nests accumulating mass during the breeding season (Dubiec \& Mazgajski 2013) dry nest mass was the sum of the component parts excluding any materials that were obviously not part of the original nest (e.g. remains of dead nestlings or eggs) and dust (Britt \& Deeming 2011).

When collected by the birds, the leaves from the two nest parts were all dead and present as either whole, skeletal or large fragments. Leaf species was identified from shape, leaf margin, veination, petiole shape and length, using reference materials collected in the field and checked with a field guide (Mitchell 1974). The mass and number of leaves found for each tree species were recorded. Similarly bark fibres and flakes were identified on the basis of colour, lenticels, texture, thickness and curvature using a hand lens, reference material from the field and a field guide (Mitchell 1974), that is, honeysuckle Lonicera sp., oak, birch, alder and hazel Corylus sp., before being counted and weighed. Moss and fern species were identified by a taxon specialist.

All measurements were taken by one observer (KBB) to eliminate error due to observer variability. Data were analysed using Minitab version 17.0. Data were tested for normality using the Kolmonov-Smirnov test prior to analysis. Differences in the amounts of the various nesting materials between the four woodland types were investigated using analysis of variance. Comparisons of the masses of the four largest proportional components of nests were made using Pearson correlations. Data for the relative percentages of materials in the nest's base and cup were not normally distributed and were converted to proportion values and normalized using the arcsin transformation before stepwise discriminant analysis was used in SPSS v. 21.0 (IBM Corp., New York) to determine whether the nest base and cup structure could be distinguished by their composition. To test whether there was any evidence of species selection in terms of tree leaf, we assumed that the thousands of leaves on a tree would mean that there was an excess of leaves within the $25 \mathrm{~m}$ radius of the nestbox. Therefore, the proportions of the three commonest tree species (oak, birch and alder), calculated by dividing the number of trees divided by the number of all trees in the $25 \mathrm{~m}$ radius provided a proxy for leaf availability. In addition, the proportion of the mass of leaves of the total mass of leaves in the nest was calculated for the same three tree species. A Wilcoxon rank test was performed to compare the difference between these two proportions against a test median of zero for oak, birch and alder, respectively. It was predicted that a significant result would indicate some preference, or avoidance, of leaves of that species of tree. A non-significant result would indicate that the proportion of leaves in a nest reflected the availability of the leaves of that species in the immediate environment. Data presented here were also tested using one-sample $t$-tests against mean values reported for two populations of Pied Flycatcher nests in North Wales as reported by Deacon et al. and for three populations of nests from central Spain reported by Moreno et al. (2009) as cited by Deeming \& Mainwaring (2015).

\section{Results}

Our designation of broad woodland types was confirmed by the percentages of trees surrounding occupied nestboxes. Within a $25 \mathrm{~m}$ radius of a tree holding a nestbox there were typically a mean of between 4 and 6 trees (a mean of 15 was observed in birch woodland) of a range of species (Figure 1). For birch woodland $77.6 \%$ of the trees surrounding a nestbox were birch.

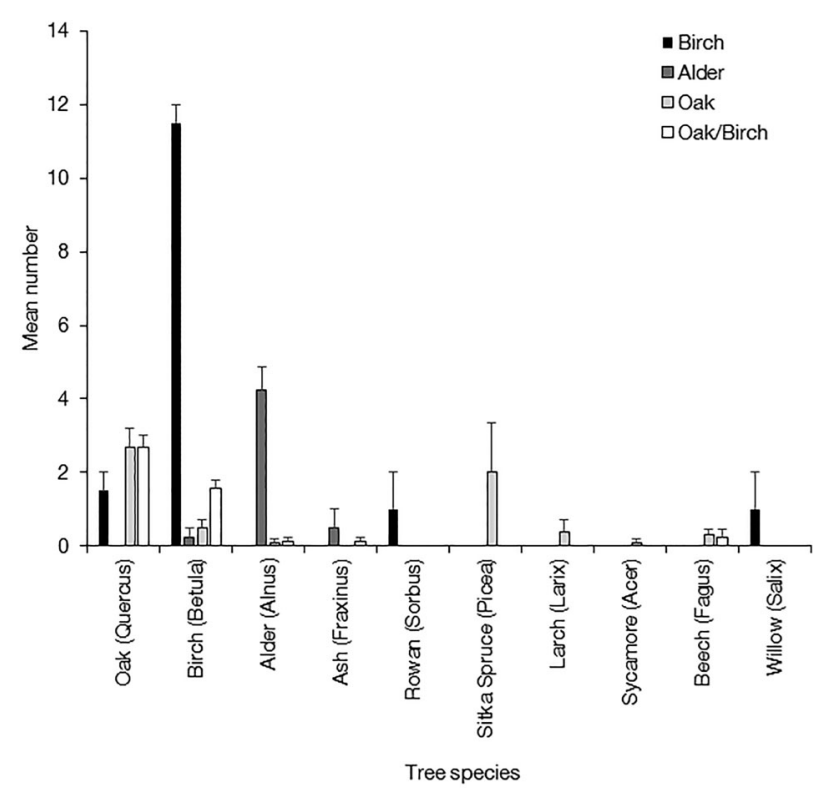

Figure 1. Mean (bars show sd) number of each tree species (genus) identified within a $25 \mathrm{~m}$ radius of nestboxes containing Pied Flycatcher nests according to woodland type surrounding the nestbox (as per the legend). Samples sizes for each woodland type are 2, 4, 10 and 9 for birch, alder, oak and oak/ birch, respectively. 
Similarly, in alder woodland $87.5 \%$ of the trees were alder, in oak $54.5 \%$ of the trees were oak and in oak/ birch woodland $93.5 \%$ of the trees were either oak or birch.

Pied Flycatcher nests had a mean mass of $20.8 \mathrm{~g}$ (se $=0.8)$, excluding a mean dust mass of $3.6 \mathrm{~g}(\mathrm{se}=0.4$ ). Descriptive statistics for the clutch size, number of hatched eggs and fledglings are shown in Table 1. Analysis of variance revealed no effect of woodland type on total nest mass, mass of plant-derived or animal-derived nest material. For individual materials only the mass of leaves (which were dead leaves collected from the ground) was significantly affected by woodland type $\left(F_{3,21}=3.56, P=0.032\right)$ but this was due to a very high mass of alder leaves in the nests from the alder site. In light of these results the data were pooled to show the mean composition of the Pied Flycatcher nests (Table 2). The nests were mainly constructed of moss, leaves, bark, grass, ferns and roots. Animal-derived material was mainly (16 nests) hair from Roe Deer Capreolus capreolus and wool from Domestic Sheep Ovis aries (6 nests) but contributed very little mass to the nests.

Dust was a significant contributor to the nest mass and was significantly positively correlated (Spearman's rho $=0.503, \mathrm{df}=23, P=0.01$ ) with the number of fledged offspring (Table 1). Excluding the dust, plantderived material formed over $99 \%$ of the nest mass.

Pearson's correlation revealed that for the four main components of the nests the amount of moss was negatively correlated (Figure 2) with the amount of grass $(r=-0.462, \mathrm{df}=23, P<0.001)$ and leaves $(r=-0.689$, $\mathrm{df}=23, P<0.001)$. The amounts of leaves and grass showed a positive relationship but this was not significant $(r=0.342, \mathrm{df}=23, P=0.094)$ and none of the variables correlated with the amount of bark.

The nest could be separated into a distinct cup and the surrounding nest material. The cup averaged less than $30 \%$ of the total nest mass, weighing $7.3 \mathrm{~g}(\mathrm{se}=0.5)$ compared with a mean of $17.3 \mathrm{~g}(\mathrm{se}=0.8)$ for the nest base. All materials were found in both parts of the nest but in differing amounts and proportions (Figure 3). Analysis of arcsin-transformed data showed that there were significant differences in the proportions of certain

Table 1. Descriptive statistics for the reproductive parameters for the 25 Pied Flycatcher nests.

\begin{tabular}{lcccc}
\hline Variable & $\begin{array}{c}\text { Clutch } \\
\text { size }\end{array}$ & $\begin{array}{c}\text { Number of } \\
\text { hatched eggs }\end{array}$ & $\begin{array}{c}\text { Number of } \\
\text { fledged young }\end{array}$ & $\begin{array}{c}\text { Clutch initiation } \\
\text { date (days; } \\
\text { 0=1 January) }\end{array}$ \\
\hline Mean & 6.68 & 5.04 & 3.64 & 131.5 \\
sd & 1.52 & 2.95 & 3.34 & 4.4 \\
Range & $2-9$ & $0-8$ & $0-8$ & $121-141$ \\
\hline
\end{tabular}

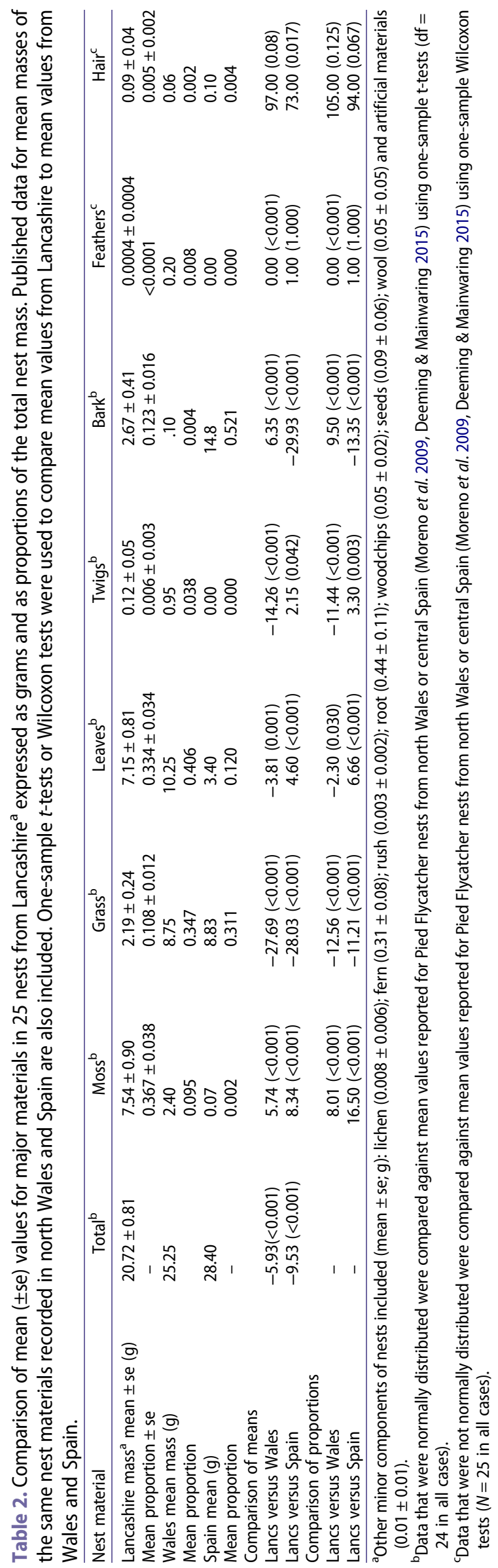




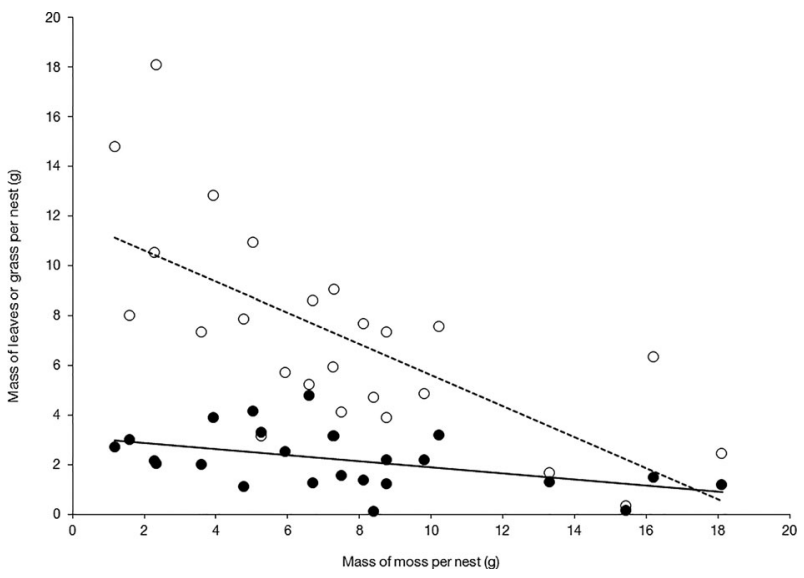

Figure 2. Relationships between mass of moss per nest and the mass of either grass (filled symbols and solid line) or leaves (open symbols and dashed line) per Pied Flycatcher nest collected in Lancashire $(N=25)$. Trendlines are least-squares regression estimates.

materials between the cup and the base. There was significantly more moss, twigs and fern in the nest bases and significantly more grass, roots and bark in the nest cup (Figure 3). Stepwise discriminant analysis revealed that the nest base and cup could be distinguished by the amounts of moss (Wilk's $\lambda=0.662$ ), fern $(\lambda=0.535)$, $\operatorname{root}(\lambda=0.448)$ and leaves $(\lambda=0.372)$.

Not all leaf material could be identified but when this was possible, Pied Flycatchers used mainly oak, birch and some beech leaves in their nests. Exceptionally, in the alder-dominated woodland the birds mainly used alder leaves, which were not found in nests from other woodland types (Figure 4). Birch leaves were found in nests from all types of woodland whereas oak leaves were found in nests from all woodland types except for alder (Figure 4). The few beech trees were limited to the oak woodland (Figure 4) and their leaves were only found in nests from this site.

A mean of $1.6(\mathrm{se}=0.2)$ species of moss were identified from each nest. Hypnum andoi (Hypnaceae) was found in all but two nests and six other moss species were present. Eurhynchium striatum (Brachytheciaceae) and Thuidium tamariscinum (Thuidiaceae) were each found in five nests where the remaining species were only found in one or two nests. The only fern found in the nests was Dryopteris filixmas (Dryopteridaceae). Bark fibres from honeysuckle were found in $75 \%$ of the 24 nests, oak was found in $46 \%$ of the nests and birch in $67 \%$ of the nests. Bark flakes were less common, with hazel being found in $17 \%$ of nests and birch in $25 \%$ of nests. Alder bark flakes were only found in one nest in the woodland dominated by alder. For all 25 sites combined there was no significant difference between the proportion of oak trees within the $25 \mathrm{~m}$ radius of the nestbox and the proportion of oak leaves in the nest (Table 3). A similar non-significant result was found for birch (Table 3), but the sample size for alder was too small for statistical analysis.

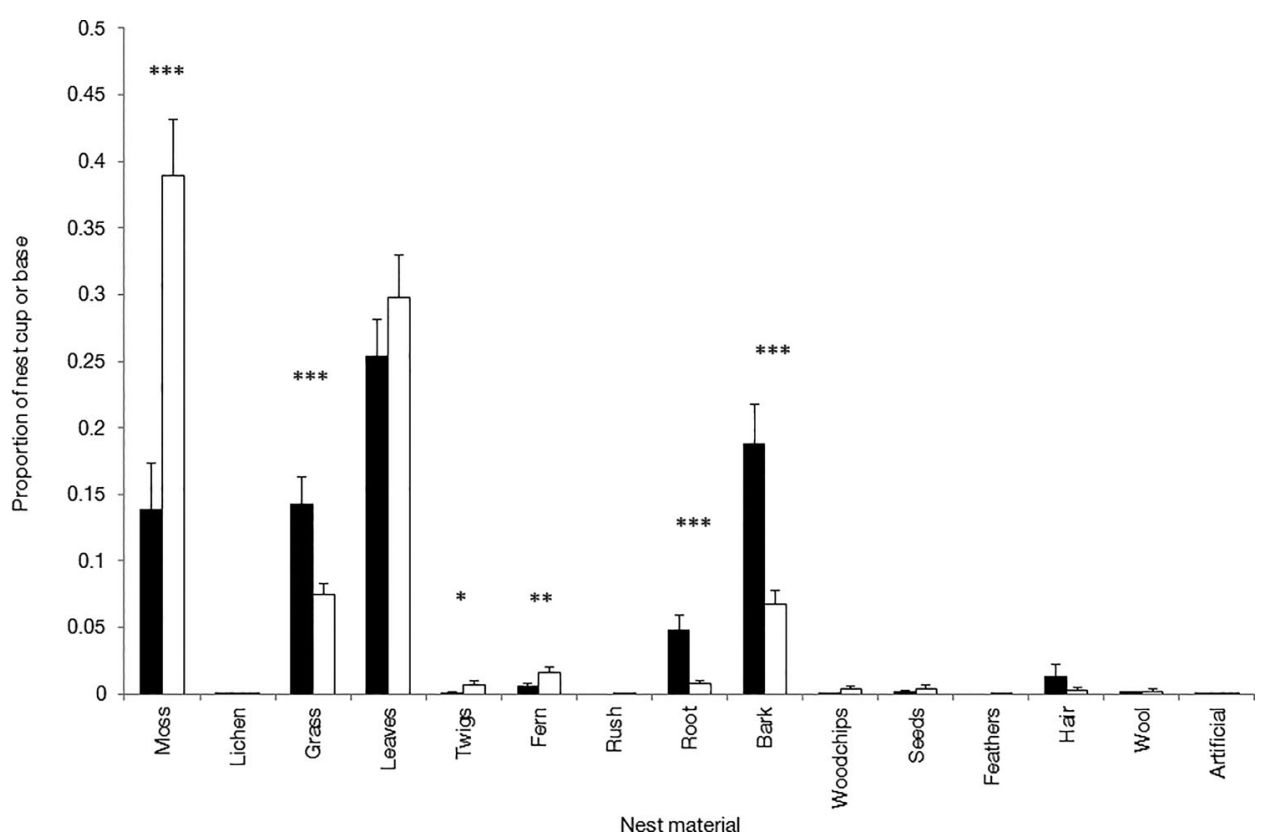

Figure 3. Proportion of different materials found in the nest base (white columns) or nest cup (black columns). Values are means (bars show se) of the mass of the material divided by the total mass of each nest part $(N=25)$. Asterisks above the columns indicate a significant effect of nest part for that material; paired $t$-tests on arcsin-transformed data, $* P<0.05, * * P<0.01$ and ${ }^{* * *} P<0.001$. 


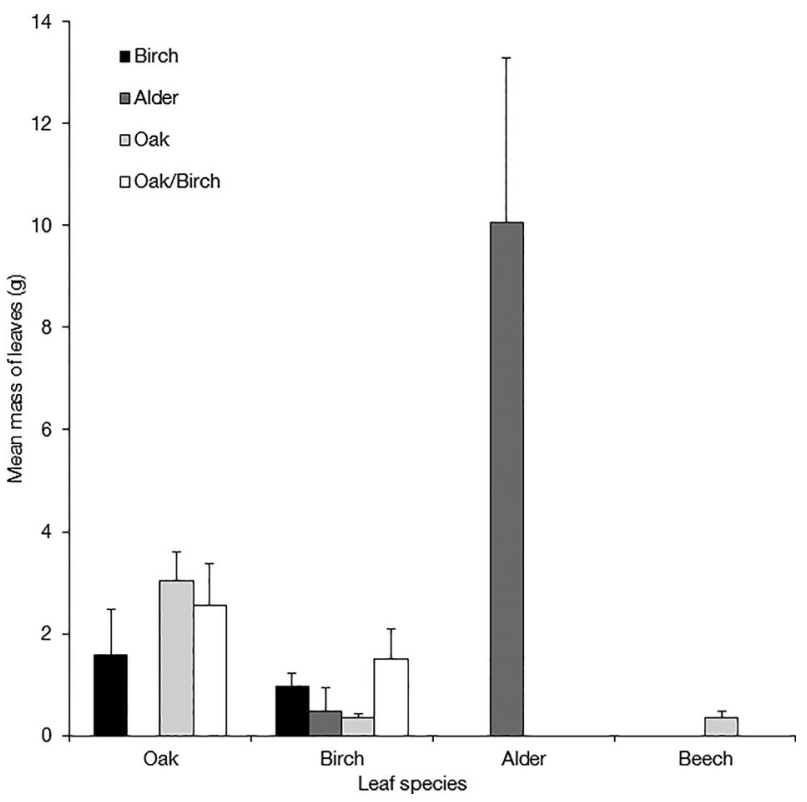

Figure 4. Mean $(+s d)$ mass of leaf species identified in Pied Flycatcher nests according to woodland type surrounding the nestbox (as per the legend). Samples sizes for each woodland type are 2, 4, 10 and 9 for birch, alder, oak and oak/birch, respectively.

\section{Comparison with other data}

Mean masses of specific material types were compared against mean values reported for Pied Flycatcher nests from north Wales collected in 2013 (Deeming \& Mainwaring 2015). Total mass did not differ significantly between the sites but there was significantly more moss and bark in nests constructed in Lancashire but significantly less grass, leaves, twigs and feathers than observed in nests from north Wales (Table 2). There was more hair in nests from Lancashire but this only approached significance (Table 2). Compared with nests constructed in central Spain (Moreno et al. 2009) nests from Lancashire were significantly lighter in mass (Table 2), and there was significantly less grass and bark, and significantly more moss, leaves, twig and hair, in Lancashire nests (Table 2).
Analyses that compared the proportions of the various materials in nests from Lancashire with those of Wales and Spain showed the same pattern as the masses (Table 2). The only exception was that there was no significant difference in the proportion of hair used in nests from Lancashire and Spain (Table 2).

\section{Discussion}

Pied Flycatchers appear to be opportunistic in their use of leaves in their nests. As we predicted the birds appeared to use leaves in the same proportion as were available in the immediate proximity of the nestbox. There was no evidence that individuals selectively preferred or avoided leaves of a particular tree species or moved between woodland areas to seek out and transport leaves of any particular species. Interestingly, compared with those in north Wales and Spain, Pied Flycatchers in Lancashire varied in the types and amounts of the materials used in nest construction. In particular, in both absolute terms and proportionally, more moss and bark were found in nests constructed in Lancashire but significantly less grass, leaves, twigs and feathers than observed in north Wales. Compared with Spain there was significantly more leaves and moss, and less grass and bark in nests constructed in Lancashire. The use of materials also varied for the cup and the nest base, with moss featuring significantly more in the base.

Pied Flycatchers nests are loosely based around a foundation of leaves, grass, bark and other plant materials, and rarely contain animal-derived materials (Stjernberg 1974, Lundberg \& Alatalo 1992, FergusonLees et al. 2011). The only available quantitative data are for nests constructed by birds in north Wales (Deacon et al. cited by Deeming \& Mainwaring 2015) and the more Mediterranean climate of central Spain (Moreno et al. 2009, Cantarero et al. 2013). Nests from North Wales were approximately $22 \%$ heavier than those from Lancashire, although this difference was not significant and did not affect the varying amounts of

Table 3. Mean, sd, median and interquartile range for the proportion of trees as a total of the trees within a $25 \mathrm{~m}$ radius of the nestbox tree, and the mean proportion of the leaves in the nest (by mass, $\mathrm{g}$ ), for oak and birch. Total sample was 25 nests. Wilcoxon values (and $P$ values) indicate the comparison of the difference between the two proportions tested against a median of zero.

\begin{tabular}{|c|c|c|c|c|}
\hline Variable & $\begin{array}{c}\text { Mean proportion of oak trees in } \\
\text { territory }\end{array}$ & $\begin{array}{c}\text { Mean proportion of oak leaves in } \\
\text { the nest }\end{array}$ & $\begin{array}{l}\text { Mean proportion of birch trees } \\
\text { in territory }\end{array}$ & $\begin{array}{l}\text { Mean proportion of birch leaves } \\
\text { in the nest }\end{array}$ \\
\hline Mean & 0.439 & 0.381 & 0.239 & 0.150 \\
\hline sd & 0.325 & 0.275 & 0.244 & 0.203 \\
\hline Median & 0.500 & 0.386 & 0.250 & 0.082 \\
\hline $\begin{array}{l}\text { Interquartile } \\
\text { range }\end{array}$ & $0.092-0.708$ & $0.167-0.643$ & $0.000-0.33$ & $0.000-0.178$ \\
\hline Wilcoxon value & \multicolumn{2}{|c|}{127.0} & \multicolumn{2}{|c|}{155.0} \\
\hline$N$ & \multicolumn{2}{|c|}{20} & \multicolumn{2}{|c|}{21} \\
\hline$P$ & \multicolumn{2}{|c|}{0.422} & \multicolumn{2}{|c|}{0.175} \\
\hline
\end{tabular}


the materials used in construction. There was significantly more moss and bark in Lancashire nests and significantly more grass, leaves, twigs and feathers in nests from Wales. In Spain the nests were significantly heavier mainly due to the higher amounts of bark and grass. It is accepted that the dimensions of the nestbox can influence the nest mass (Deeming \& Mainwaring 2015) and the dimensions for the Spanish nestboxes were slightly larger (with the base measuring $130 \times 115 \mathrm{~mm}$; Alejandro Cantarero, pers. comm.) and the Welsh nestboxes were even larger $(150 \times 115 \mathrm{~mm}$; Hannah Rowland, pers. comm.). However, the heaviest nests were from Spain and the differences in amounts of materials used in the nests between these sites were so large that conversion to proportions of the total nest mass did not have any appreciable effect on the general conclusions.

As a species these data show that Pied Flycatchers are apparently not constrained in their use of nest materials but there is considerable geographical variation. Other species exhibit geographical variation in the materials used in their nests. For instance, the amount of moss in both Great Tit and Blue Tit nests varies within the UK and between Spain and the UK (Deeming \& Mainwaring 2015). It was interesting that in the nests described from Lancashire, moss was also a large component of the nest but it was largely absent in nests from Wales or Spain. Moreover, moss seemed to replace leaves, and to a lesser extent grass, in some of the nests and was not correlated with the amount of bark in the structure. Combined, moss, leaves and grass formed about $80 \%$ of the total nest mass in Lancashire, which is similar to what is observed in Wales but not in Spain where Pied Flycatchers seem to use more bark. Whether this reflects availability we cannot say but it would be interesting to compare the thermal and physical properties of the different combinations of moss, leaves and grass used by this species to determine whether the same insulatory properties are achieved.

Our data add to a general understanding that nest construction behaviour exhibits phenotypic plasticity (Walsh et al. 2010, 2011). Such variation can contribute to physical properties of the nests, such as the insulatory value of the whole nests that correlates with latitude, temperature and the amounts of grass recorded in Common Blackbird nests (Mainwaring et al. 2014). It would be interesting to determine whether Pied Flycatchers in other parts of their geographical range use differing amounts or other types of material.

The evidence suggests that, in Lancashire, the Pied Flycatchers were opportunistic in their use of tree leaves in the nests - the tree species used reflected the available source of leaves within the territory. This implies that leaves of any particular tree species have no characteristic that is especially valued by the birds. Moreover, the use of leaves in a nest appears to reflect an opportunist behaviour where birds simply use the first leaves they encounter when they leave the nestbox. As indicated above opportunistic use of nest materials, particularly for lining the cup, is also observed in tit species (Britt \& Deeming 2011, Surgey et al. 2012). Although captive Zebra Finches Taeniopygia guttata appeared to be selective in terms of colour used for nest building (Muth et al. 2013), wild tit species were not (Surgey et al. 2012). Moreover, the physical characteristics of the materials used in the nest not only appeared to be important in captive Zebra Finches provided with a limited supply of materials (Bailey et al. 2014, Muth \& Healy 2014) but also in wild Common Blackbirds (Biddle et al. 2015) and Eurasian Bullfinches Pyrrhula pyrrhula (Biddle et al. forthcoming). In these latter two, open-nesting species the size, strength and rigidity of the materials vary between different parts of the nest and reflect particular roles in nest construction or support (Biddle et al. 2015, forthcoming). By contrast, for a nest in a cavity the mechanical properties of different parts may not be so crucial because of the physical support offered by the nest-cavity walls. As a consequence moss is commonly used by cavity-nesting tit species (Deeming \& Mainwaring 2015). The physical characteristics of leaves may not be an important consideration for Pied Flycatchers. Although it was possible to distinguish between the nest base and the cup on the basis of the materials used we do not know whether this has any consequences for the functional properties of the structure. More research is needed to determine the roles (e.g. insulation or physical support) which the various materials used in a nest play when constructed within a cavity or nestbox, and how these vary between species.

Leaves form a high proportion of the base (approximately $40 \%$ of total mass) in Pied Flycatcher nests in Wales (Deacon et al. cited by Deeming \& Mainwaring 2015) but only around 10-15\% in Spain, where grass appears to be the preferred nest material (Moreno et al. 2009). In Lancashire, leaves were around $29 \%$ of the total mass but moss was almost $31 \%$. By contrast, in Spain, moss was hardly used (Moreno et al. 2009, Cantarero et al. 2013) and it only formed less than $10 \%$ of Welsh nests (Deacon et al. cited by Deeming \& Mainwaring 2015). It is interesting that Moreno et al. (2009) suggested that European Ficedula species did not use moss in their nests 
because they over-winter in dry woodlands and savannah in Africa. Contrary to this view, Red-breasted Flycatchers Ficedula parva constructed nests that were 85\% moss (Mitrus \& Drężek 2016) and Pied Flycatchers in Lancashire also used a lot of moss. In the latter case the birds also seemed to use one species more commonly than other species. We are, however, unable to determine whether the birds are exhibiting a preference for this one species or whether this is also opportunistic behaviour with individual birds collecting the moss species closest to the nest. The latter explanation may be more likely because $H$. andoi grows on the boles of most trees in the woodland. Given the potential role for moss as a moisture absorber (Mitrus \& Drężek 2016) it would be interesting to investigate the relative abundance of moss species in the woodlands and the subsequent use by the birds in their nests.

The consequences of the differences in nest composition are as yet unclear. Hilton et al. (2004) showed that different animal-derived materials had better insulatory properties, which were in turn better than grass, but other plant-derived materials were not tested. Although amounts of grass correlated well with insulatory values in Common Blackbird nests the evidence to link the functional insulation offered by a nest wall with a particular nest material is somewhat lacking. The amount of grass in the nests of European Robins significantly correlated with insulatory value but the relationship was weak (Taberner Cerezo \& Deeming 2016). Further research is needed to determine whether insulatory values are related to the amounts of particular materials in a nest wall or whether the wall in its entirety is the key feature in nest insulation.

This report highlights that Pied Flycatchers exhibit phenotypic plasticity in nest construction behaviour. Although this can be observed across many hundreds of kilometres between northern England, Wales and Spain, this study also demonstrates that this plasticity can be observed on a very small scale of less than $3-4 \mathrm{~km}$. We have little understanding why geographically separated populations utilize different nesting materials and more research is needed to document this geographical variation. Also, we have no understanding of the cognitive processes used by birds when they decide upon the materials they choose for their nests. Although Zebra Finches are a useful model in this regard the materials used in many studies are artificial and it would be interesting to attempt to determine the choices that wild birds are making during nest construction. Research that attempts to manipulate choice of materials under natural conditions may be very informative about nest construction behaviour. The consequences of this variability in nest materials also need to be documented in order to better understand how differences in the type and amount of materials used by one population impact upon the functional properties of the nests in terms of structure and insulation.

\section{Acknowledgements}

This paper is dedicated to the memory of Chester Mockett and Keith Woods who started this long-running Pied Flycatcher project. Thanks also to John Wilson for collecting nests and the landowners - Lord Reay, Lord Shuttleworth, Richard Johnson, Karl Oyston and Rodney Everett - for permission to use their woodlands. We are grateful to Andy McLay of Natural England for identification of the moss species and to Tom Pike for conversations about statistical analysis. We are grateful to the reviewers of the various drafts of the submission for their constructive comments that improved this manuscript.

\section{ORCID}

D. Charles Deeming (D) http://orcid.org/0000-0002-9587-6149

\section{References}

Álvarez, E., Belda, E.J., Verdejo, J. \& Barba, E. 2012. Variation in Great Tit nest mass and composition and its breeding consequences: a comparative study in four Mediterranean habitats. Avian Biol. Res. 6: 39-46.

Bailey, I.E., Morgan, K.V., Bertin, M., Meddle, S.L. \& Healy, S.D. 2014. Physical cognition: birds learn the structural efficacy of nest material. Proc. R. Soc. B 281: 20133225.

Biddle, L., Deeming, D.C. \& Goodman, A.M. 2015. Morphology and biomechanics of the nests of the Common Blackbird Turdus merula. Bird Study 62: 87-95.

Biddle, L., Deeming, D.C. \& Goodman, A.M. Forthcoming. Patterns of construction of nests provide insight into nestbuilding behaviour. PeerJ.

Britt, J. \& Deeming, D.C. 2011. First egg date and air temperature affect nest construction in Blue Tits Cyanistes caeruleus but not in Great Tits Parus major. Bird Study 58: 78-89.

Cantarero, A., López-Arrabé, J., Rodríguez-García, V., González-Braojos, S., Ruiz-de-Castañeda, R., Redondo, A.J. \& Moreno, J. 2013. Factors affecting the presence and abundance of generalist ectoparasites in nests of three sympatric hole-nesting bird species. Acta Ornithol. 48: 39-54.

Cooper, C.B., Bailey, R. L. \& Leech, D.I. 2015. The role of citizen science in studies of avian reproduction. In Deeming, D.C. and Reynolds, S.J. (eds.) Nests, Eggs, and Incubation: New Ideas about Avian Reproduction, 208220. Oxford University Press, Oxford.

Cramp, S. \& Perrins, C.M. 1993. Handbook of the Birds of Europe, the Middle East and North Africa. The Birds of the Western Palearctic. Volume VII. Flycatchers to Shrikes. Oxford University Press, Oxford.

Deeming, D.C. \& Mainwaring, M.C. 2015. Functional properties of nests. In Deeming, D.C. and Reynolds, S.J. (eds.) Nests, Eggs, and Incubation: New Ideas About Avian Reproduction, 29-49. Oxford University Press, Oxford. 
Dubiec, A. \& Mazgajski, T.D. 2013. Nest mass variation over the nesting cycle in the Pied Flycatcher (Ficedula hypoleuca). Avian Biol. Res. 6: 127-132.

Dubiec, A., Góźdź, I. \& Mazgajski, T.D. 2013. Green materials in avian nests. Avian Biol. Res. 6: 133-146.

Ferguson-Lees, J., Castell, R. \& Leech, D. 2011. A Field Guide to Monitoring Nests. British Trust for Ornithology, Thetford.

García-Navas, V., Valera, V. \& Griggio, M. 2015. Nest decorations: an 'extended' female badge of status? Anim. Behav. 99: 95-107.

Hilton, G.M., Hansell, M.H., Ruxton, G.D., Reid, J.M. \& Monaghan, P. 2004. Using artificial nests to test importance of nesting material and nest shelter for incubation energetics. Auk 121: 777-787.

Lundberg, A. \& Alatalo, R.V. 1992. The Pied Flycatcher. T \& A D Poyser, London.

Mainwaring, M.C., Deeming, D.C., Jones, C.I. \& Hartley, I.R. 2014. Adaptive latitudinal variation in Common Blackbird Turdus merula nest characteristics. Ecol. Evol. 4: 841-851.

Mitchell, A. 1974. A Field Guide to the Trees of Britain and Northern Europe. Collins, London.

Mitrus, C. \& Drężek, A. 2016. Plasticity in nest composition in relation to nest-site characteristics in the Red-breasted Flycatcher (Ficedula parva). Avian Biol. Res. 9: 71-75.

Moreno, J., Merino, S., Lobato, E., Ruiz-de-Castañeda, R., Martínez de la Puente, J., Del Cerro, S. \& Rivero-De Aguilar, J. 2009. Nest-dwelling ectoparasites of two sympatric hole-nesting passerines in relation to nest composition: an experimental study. Ecoscience 16: 418-427.
Muth, F. \& Healy, S.D. 2014. Zebra finches select nest material appropriate for a building task. Anim. Behav. 90: 237-44.

Muth, F., Steele, M. \& Healy, S.D. 2013. Colour preferences in nest-building zebra finches. Behav. Proc. 99: 106-111.

Perrins, C.M. 1979. British Tits. Collins, London.

Sergio, F., Blas, J., Blanco, G., Tanferna, A., López, L., Lemus, J.A. \& Hiraldo, F. 2011. Raptor nest decorations are a reliable threat against conspecifics. Science 331: 327330.

Stjernberg, M. 1974. Nest-building by the Pied Flycatcher Ficedula hypoleuca. Ornis Fenn. 51: 85-109.

Suárez-Rodríguez, M., López-Rull, I. \& Macías Garcia, C. 2013. Incorporation of cigarette butts into nests reduces nest ectoparasite load in urban birds: new ingredients for an old recipe? Biol. Lett. 9: 20120931.

Surgey, J., du Feu, C.R. \& Deeming, D.C. 2012. Opportunistic use of a wool-like artificial material as lining of tit (Paridae) nests. Condor 114: 385-392.

Taberner Cerezo, A. \& Deeming, D.C. 2016. Construction materials reveal nest building behaviour in the European Robin (Erithacus rubecula). Avian Biol. Res. 9: 98-102.

Walsh, P.T., Hansell, M., Borello, W.D. \& Healy, S.D. 2010. Repeatability of nest morphology in African weaver birds. Biol. Lett. 6: 149-151.

Walsh, P.T., Hansell, M., Borello, W.D. \& Healy, S.D. 2011. Individuality in nest building: Do southern Masked weaver (Ploceus velatus) males vary in their nest-building behaviour? Behav. Proc. 88: 1-6. 